\title{
Synthesis and Characterization of Europium-Doped Zinc Oxide Photocatalyst
}

\author{
Anukorn Phuruangrat, ${ }^{1}$ Oranuch Yayapao, ${ }^{2}$ Titipun Thongtem, ${ }^{3}$ and Somchai Thongtem ${ }^{2}$ \\ ${ }^{1}$ Department of Materials Science and Technology, Faculty of Science, Prince of Songkla University, Hat Yai, Songkhla 90112, Thailand \\ ${ }^{2}$ Department of Physics and Materials Science, Faculty of Science, Chiang Mai University, Chiang Mai 50200, Thailand \\ ${ }^{3}$ Department of Chemistry, Faculty of Science, Chiang Mai University, Chiang Mai 50200, Thailand
}

Correspondence should be addressed to Anukorn Phuruangrat; phuruangrat@hotmail.com and Somchai Thongtem; schthongtem@yahoo.com

Received 1 January 2014; Accepted 20 February 2014; Published 27 March 2014

Academic Editor: Abdelwahab Omri

Copyright (C) 2014 Anukorn Phuruangrat et al. This is an open access article distributed under the Creative Commons Attribution License, which permits unrestricted use, distribution, and reproduction in any medium, provided the original work is properly cited.

Single crystalline flower-like $\mathrm{ZnO}$ and Eu-doped $\mathrm{ZnO}$ structures were successfully synthesized via a sonochemical method. Structures, morphologies, and photocatalytic activities of the as-synthesized samples were determined using X-ray diffraction, scanning electron microscopy, transmission electron microscopy, Raman spectroscopy, X-ray photoelectron spectroscopy, and ultraviolet-visible absorption spectroscopy. The photocatalytic activities of the as-synthesized samples were evaluated by the degradation of methylene blue in aqueous solutions under UV light. The photocatalytic results indicate that the as-synthesized Eudoped $\mathrm{ZnO}$ shows good photocatalytic activity and could be considered as a promising photocatalyst for dye waste water treatment.

\section{Introduction}

In recent years, organic dyes in waste water have become one of the main pollutants in our daily lives. To solve this problem, semiconducting photocatalysts are the promising materials to degrade the organic pollutants in waste water because they proved to be the highly efficient catalysts for environmental remediation and energy conversion purposes $[1,2]$. In photocatalytic process, valence band holes generated by photons from light source such as UV and visible light interact with $\mathrm{H}_{2} \mathrm{O}$ or $\mathrm{OH}^{-}$adsorbed on the catalytic surfaces to generate hydroxyl radical (.OH), and electrons in the conduction band interact with adsorbed $\mathrm{O}_{2}$ to yield. $\mathrm{O}_{2}{ }^{-}$radical. These radicals are highly reactive and unselective oxidants. Among them, $\mathrm{ZnO}$ and $\mathrm{TiO}_{2}$ are the most extensively used photocatalysts due to their high photocatalytic activity and excellent chemical and mechanical stability and because they are nontoxic and inexpensive. Furthermore, $\mathrm{ZnO}$ is also a suitable alternative photocatalyst to $\mathrm{TiO}_{2}$ because it is cheaper and has almost the same band gap energy. In addition, $\mathrm{ZnO}$ shows better performance compared to $\mathrm{TiO}_{2}$ in the degradation of several organic contaminants in both acidic and basic media, which has stimulated many researchers to further explore the properties of $\mathrm{ZnO}$ in many photocatalytic reactions [3-5].

$\mathrm{ZnO}$ is a semiconductor with wide band gap of $3.37 \mathrm{eV}$ and large exciton binding energy of $60 \mathrm{meV}$ at room temperature, including excellent chemical and thermal stability. It has been widely used for optical, electrical, optoelectronic, catalytic, and photochemical properties, including optical waveguides and transparent conducting coatings [6-8]. It is the most important material to eliminate organic pollutants in waste water such as reactive brilliant red K-2BP [9], methylene blue $[3,4,10]$, Acridine orange [5], rhodamine B $[7,10]$, methyl orange [11], and polyvinyl alcohol in aqueous solutions [12]. Sun et al. [3] reported that dumbbell-shaped $\mathrm{ZnO}$ photocatalyst showed a $99.6 \%$ decolorization efficiency of MB within $75 \mathrm{~min}$ under UV light $(365 \mathrm{~nm})$ which is higher than the commercial $\mathrm{ZnO}$ performance. Xu et al. [11] claimed that highly crystalline hexagonal $\mathrm{ZnO}$ nanorod assembled flowers, synthesized by a hydrothermal method, were able to significantly degrade methylene blue (MB) and rhodamine $\mathrm{B}(\mathrm{RhB})$ at $91 \%$ and $80 \%$ within $140 \mathrm{~min}$. To improve photocatalytic activities, lanthanide ions with 


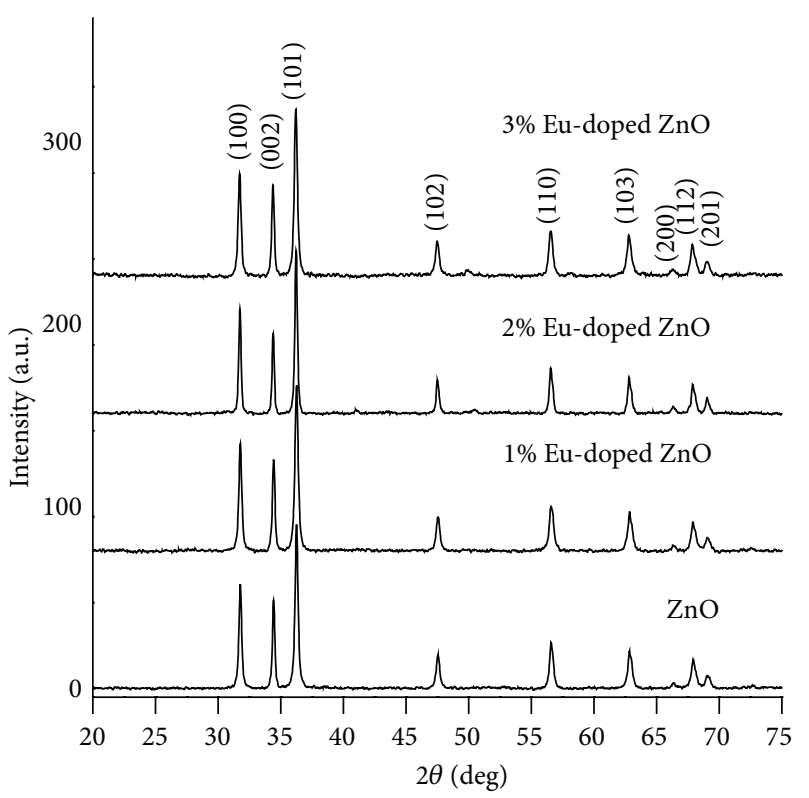

(a)

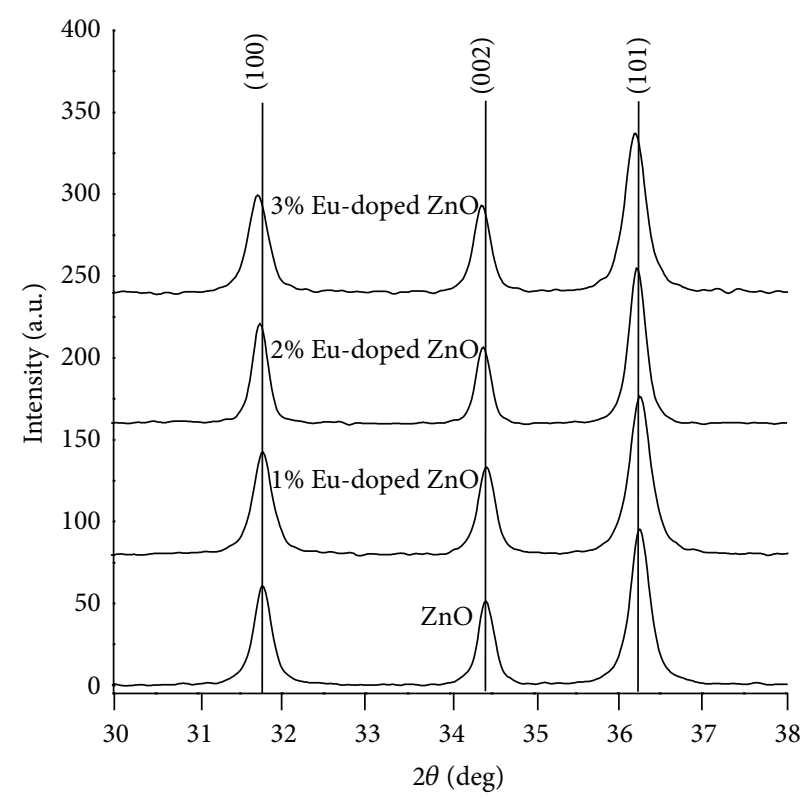

(b)

Figure 1: XRD patterns at $2 \theta$ of (a) $20^{\circ}-75^{\circ}$ and (b) $30^{\circ}-38^{\circ}$ of the as-synthesized undoped and Eu-doped $\mathrm{ZnO}$ samples synthesized by sonochemical method for $5 \mathrm{~h}$.

4f electron configuration have been doped into $\mathrm{ZnO}$ to delay recombination rate of the electron-hole pairs and to effectively eliminate the organic dye pollutants in waste water [2]. The lanthanide ionic-doped $\mathrm{ZnO}$, such as $\mathrm{Sm}^{3+}, \mathrm{Nd}^{3+}$, $\mathrm{La}^{3+}, \mathrm{Dy}^{3+}$, and $\mathrm{Ce}^{3+}[5,8,13-15]$, has been demonstrated to be more effective in promoting the photocatalytic activities than pure $\mathrm{ZnO}$. Therefore, $\mathrm{ZnO}$ doped with Europium will be an efficient way to improve the photocatalytic activity, because the electrons are effectively trapped by the supplied chemical valence $\left(\mathrm{Eu}^{2+}\right.$ and $\left.\mathrm{Eu}^{3+}\right)$ sites [16].

In this work, the Eu-doped $\mathrm{ZnO}$ samples were synthesized by a sonochemical method. The photocatalytic activities of the as-synthesized samples for the methylene blue (MB) photodegradation were investigated and discussed.

\section{Experimental Details}

The zinc nitrate hexahydrate $\left(\mathrm{Zn}\left(\mathrm{NO}_{3}\right)_{2} \cdot 6 \mathrm{H}_{2} \mathrm{O}\right)$, Europium nitrate hexahydrate $\left(\mathrm{Eu}\left(\mathrm{NO}_{3}\right)_{3} \cdot 6 \mathrm{H}_{2} \mathrm{O}\right)$ as zinc and Europium sources, and sodium hydroxide $(\mathrm{NaOH})$ were used without further purification.

To synthesize $0-3 \%$ Eu-doped $\mathrm{ZnO}$, the 0.005 mole $\left(\mathrm{Zn}\left(\mathrm{NO}_{3}\right)_{2} \cdot 6 \mathrm{H}_{2} \mathrm{O}\right)$ and $0-3 \mathrm{~mol} \% \mathrm{Eu}\left(\mathrm{NO}_{3}\right)_{3} \cdot 6 \mathrm{H}_{2} \mathrm{O}$ were dissolved in $100 \mathrm{~mL}$ deionized water under rigorous stirring until complete dissolution. Subsequently, $3 \mathrm{M} \mathrm{NaOH}$ solution was slowly dropped into these solutions until reaching at the $\mathrm{pH} 10$ and the solutions became colorless. Then, the colorless solutions were sonicated in ultrasonic bath for $5 \mathrm{~h}$. The precipitates were synthesized, filtered, washed with water and ethanol several times, dried, and collected for further characterization.

The products were characterized by X-ray diffraction (XRD) on a Philips X'Pert MPD X-ray diffractometer equipped with $\mathrm{Cu} \mathrm{K}_{\alpha}$ radiation over a range from $20^{\circ}$ to $75^{\circ}$ using a scanning rate of $0.02 \mathrm{deg} / \mathrm{s}$. Morphologies of the samples were recorded by field emission scanning electron microscopy (FE-SEM) and transmission electron microscopy (TEM). FE-SEM images were carried out using a JEOL, JSM $6335 \mathrm{~F}$ scanning electron microscope at $20 \mathrm{kV}$. TEM images were taken by a JEOL, JEM 2010 transmission electron microscope with an accelerating voltage of $200 \mathrm{kV}$. Raman spectra were recorded on a HORIBA JOBIN YVON T64000 spectrophotometer operated using $30 \mathrm{~mW} \mathrm{He}-\mathrm{Ne}$ red laser with $632.8 \mathrm{~nm}$ wavelength in the range of $100-1200 \mathrm{~cm}^{-1}$. $\mathrm{X}$-ray photoelectron spectroscopy (XPS) of the products was carried out via an Axis Ultra DLD, Kratos Analytical Ltd., with a monochromated $\mathrm{Al} \mathrm{K}_{\alpha}(1486.6 \mathrm{eV})$ radiation as the excitation source at $15 \mathrm{kV}$. All obtained spectra were calibrated to a C 1s electron peak at $285.1 \mathrm{eV}$.

Photocatalytic activities of the as-synthesized samples were tested by measuring the degradation of methylene blue $(\mathrm{MB})$ in an aqueous solution under a UV radiation. Each $0.15 \mathrm{~g}$ photocatalyst was suspended in $100 \mathrm{~mL}$ of $10^{-5} \mathrm{M} \mathrm{MB}$ aqueous solutions, which were magnetically stirred for $60 \mathrm{~min}$ in the dark to establish an adsorption-desorption equilibrium of $\mathrm{MB}$ on the surface of the photocatalyst. Then the light was turned on to initiate the test. The solution was analyzed by a Lambda 25 spectrometer, using $450 \mathrm{~W}$ of Xe lamp with wavelength of $664 \mathrm{~nm}$ as maximum absorption of MB. Decolorization efficiency (\%) was calculated using the following equation:

$$
\text { Decolorization efficiency }(\%)=\frac{C_{0}-C_{t}}{C_{0}} \times 100 \text {, }
$$

where $C_{0}$ is the initial concentration of $\mathrm{MB}$ and $C_{t}$ is the concentration of $\mathrm{MB}$ after light irradiation. 


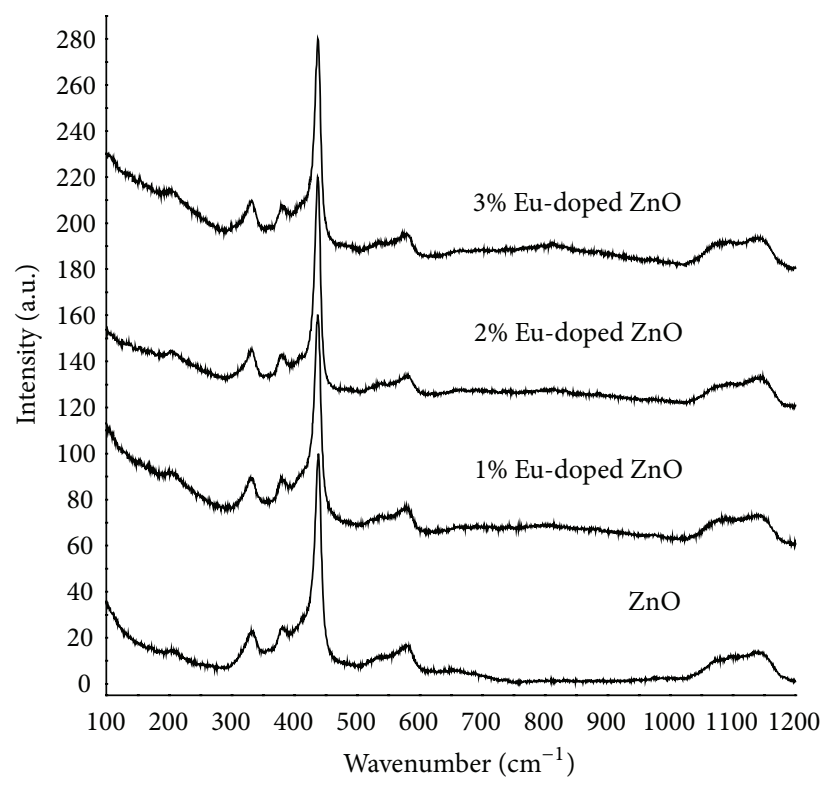

Figure 2: Raman spectra of the as-synthesized undoped and Eu-doped $\mathrm{ZnO}$ samples synthesized by sonochemical method for $5 \mathrm{~h}$ using He-Ne red laser with $632.8 \mathrm{~nm}$ wavelength.

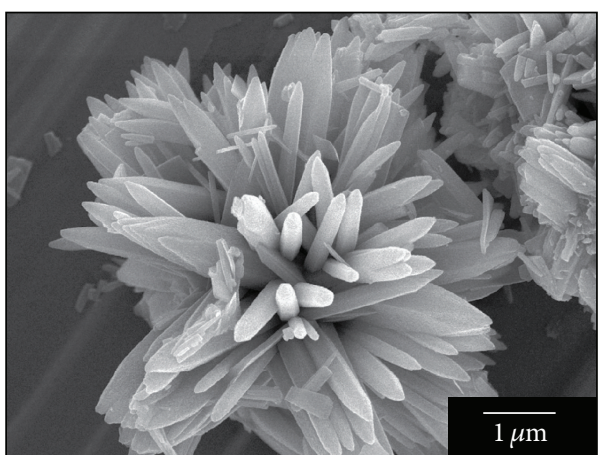

(a)

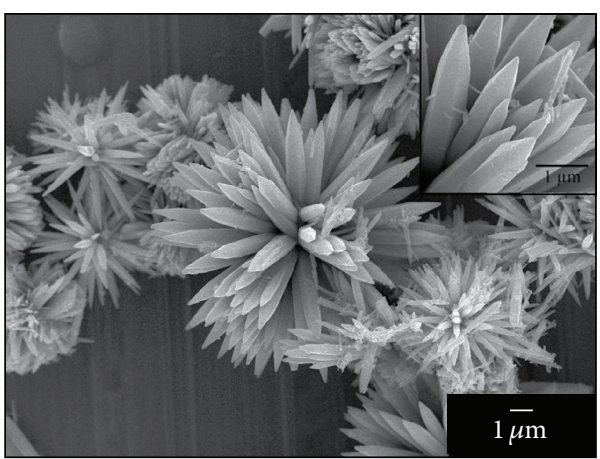

(c)

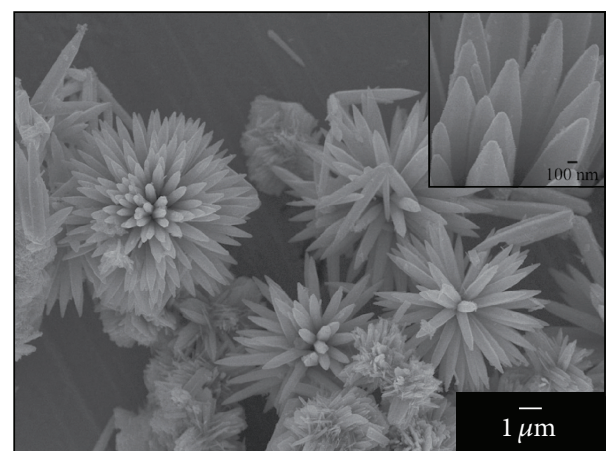

(b)

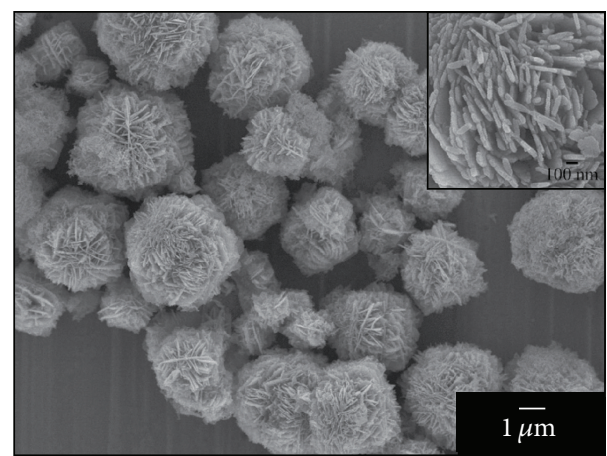

(d)

Figure 3: SEM images of (a) $0 \%$, (b) $1 \%$, (c) $2 \%$, and (d) $3 \%$ of Eu-doped $\mathrm{ZnO}$.

\section{Results and Discussion}

XRD patterns of $\mathrm{Zn}_{1-x} \mathrm{Eu}_{x} \mathrm{O}(x=0,0.01,0.02$, and 0.03$)$ synthesized by sonochemical radiation for $5 \mathrm{~h}$ are shown in Figure 1(a). The diffraction peaks of undoped $\mathrm{ZnO}$ sample appeared at $2 \theta=31.80^{\circ}, 34.46^{\circ}, 36.28^{\circ}, 47.58^{\circ}, 56.62^{\circ}, 62.88^{\circ}$, $66.40^{\circ}, 68.00^{\circ}$, and $69.12^{\circ}$ which were, respectively, identified to the (100), (002), (101), (102), (110), (103), (200), (112), and (201) diffraction planes of wurtzite hexagonal $\mathrm{ZnO}$ structure in accordance with the database of the JCPDS number 361451 [17]. However, the XRD patterns of $\mathrm{Zn}_{1-x} \mathrm{Eu}_{x} \mathrm{O}(x=$ $0.01,0.02$, and 0.03 ) were still the same as that of pure 


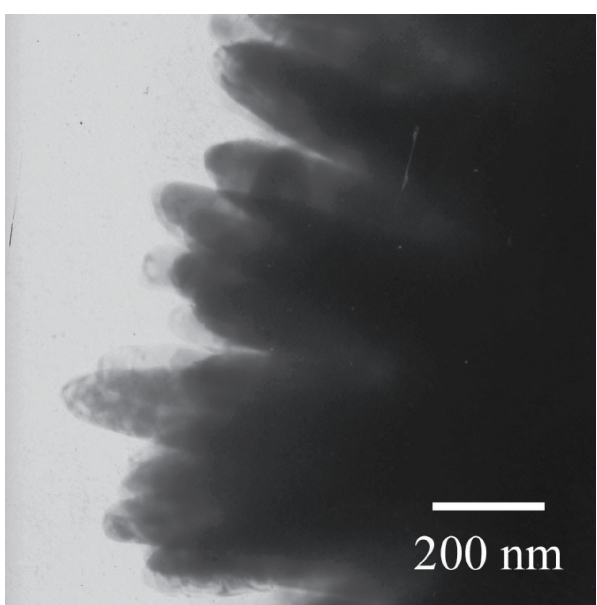

(a)

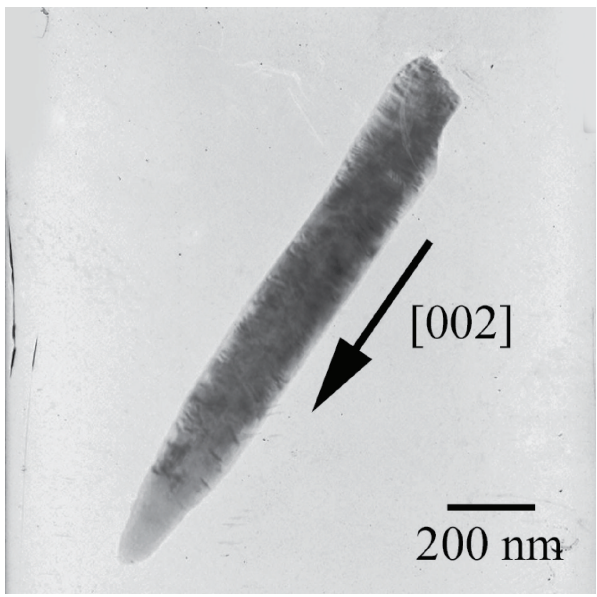

(c)

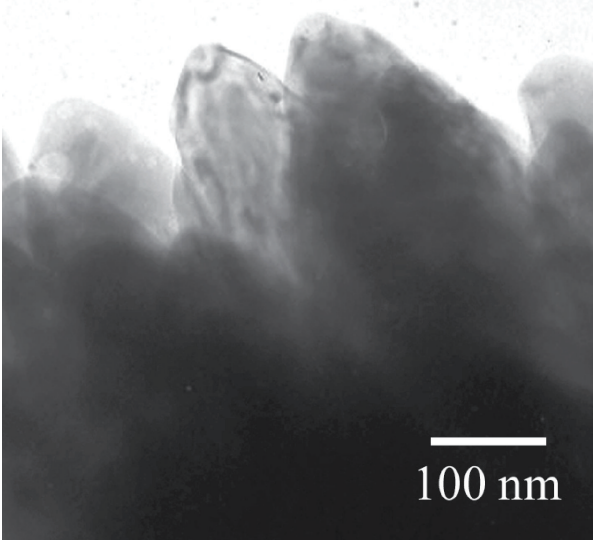

(b)

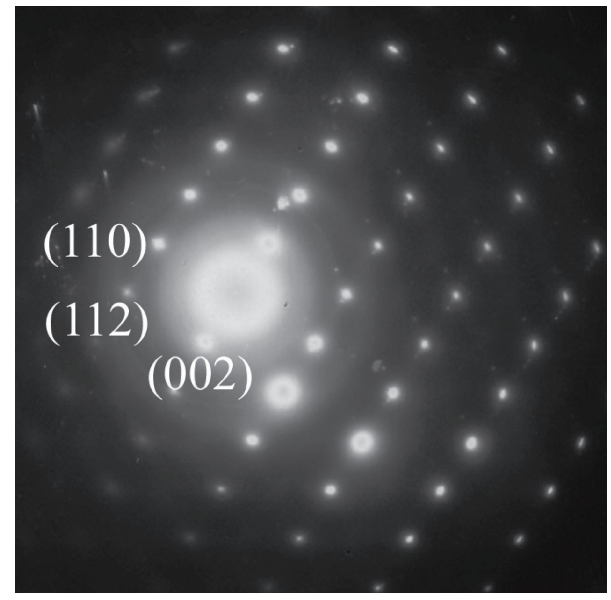

(d)

FIGURE 4: TEM images and SAED pattern of flowers of hexagonal pyramid tips $\mathrm{ZnO}$ nanorod.

wurtzite hexagonal $\mathrm{ZnO}$ structure without detection of any secondary phases. They indicated that $\mathrm{Eu}^{3+}$ ions of the doped $\mathrm{ZnO}$ samples were only incorporated in the $\mathrm{ZnO}$ lattice. The changes in the $2 \theta$ of the diffraction planes of (100), (002), and (101) peaks at $2 \theta=30.00^{\circ}-38.00^{\circ}$ for $\mathrm{Zn}_{1-x} \mathrm{Eu}_{x} \mathrm{O}(x=0.01$, 0.02 , and 0.03 ) with increasing concentration of Eu doping are shown in Figure 1(b). They shifted to lower $2 \theta$ due to the ionic radius of $\mathrm{Eu}^{3+}(0.95 \AA)$ being larger than that of $\mathrm{Zn}^{2+}$ $(0.74 \AA)[18,19]$.

Typical wurtzite $\mathrm{ZnO}$ belongs to the space group $C_{6 v}^{4}$ with two formula units per primitive cell. A primitive $\mathrm{ZnO}$ cell has four atoms, each of which occupies $C_{3 v}$ sites, leading to 12 phonon branches (nine optical and three acoustic branches). Group theory predicts vibration modes at the zone center optical phonons: $A_{1}+2 B_{1}+E_{1}+2 E_{2}$, where $B_{1}$ mode keeps silence and $A_{1}, E_{1}$ are polar modes, both Raman and IR active and thus split into transverse-optical (TO) and longitudinal-optical (LO) phonons, while two $\mathrm{E}_{2}$ modes that denoted low-wavenumber $E_{2 L}$ and high-wavenumber $E_{2 H}$ modes are nonpolar. The $\mathrm{E}_{2 \mathrm{~L}}$ mode is mainly associated with the vibration of the zinc sublattice, while the $\mathrm{E}_{2 \mathrm{H}}$ mode involves the oxygen motion and characteristic of the wurtzite structure. The $\mathrm{B}_{1}$ mode is silent $[20,21]$.

Figure 2 shows the Raman spectra of the as-synthesized undoped and $\mathrm{Eu}$-doped $\mathrm{ZnO}$ nanocrystals excited by red laser. Pure $\mathrm{ZnO}$ shows Raman peak at $439 \mathrm{~cm}^{-1}$ which is attributed to $\mathrm{E}_{2 \mathrm{H}}$ mode of the $\mathrm{ZnO}$ nonpolar optical phonons. The bands at 327 and $380 \mathrm{~cm}^{-1}$ are assigned as the $2 \mathrm{E}_{2 \mathrm{~L}}$ and the TO mode with $A_{1}$ symmetry $\left(A_{1 T}\right)$, respectively [20]. The bands at $584 \mathrm{~cm}^{-1}$ correspond to $\mathrm{E}_{1}$ symmetry with LO modes. Generally, the $\mathrm{E}_{1}(\mathrm{LO})$ peak is caused by defects due to $\mathrm{O}$-vacancies, $\mathrm{Zn}$-interstitials or these complexes, and free carriers [21, 22]. Moreover, the Raman peaks of $\mathrm{E}_{2 \mathrm{H}}$ evidently shift towards a low wavenumber from $439 \mathrm{~cm}^{-1}$ of undoped $\mathrm{ZnO}$ to $437 \mathrm{~cm}^{-1}$ of $3 \% \mathrm{Eu}$-doped $\mathrm{ZnO}$ [22], confirming an effective substitution of $\mathrm{Zn}^{2+}$ ions by $\mathrm{Eu}^{3+}$ ions in the assynthesized nanocrystals, in accordance with the detection by the XRD analysis.

Morphologies of the pure and doped $\mathrm{ZnO}$ samples were characterized by FE-SEM as shown in Figure 3. In this research, the products are flower-like structures composed of hexagonal pyramid tips with edge length of $1.0-1.5 \mu \mathrm{m}$ and 


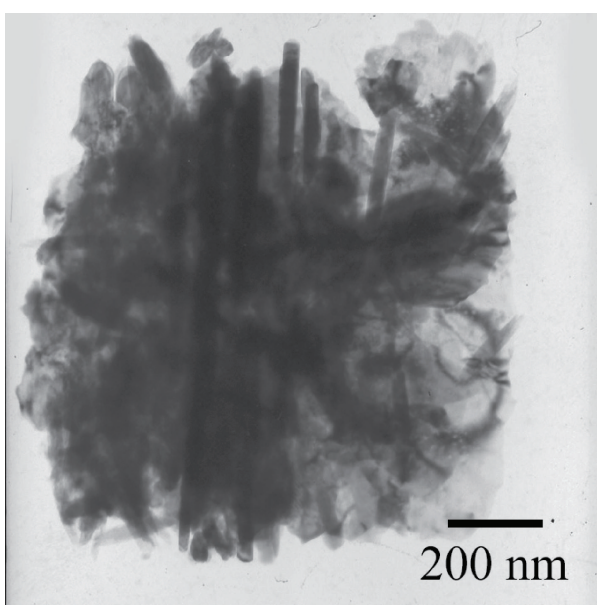

(a)

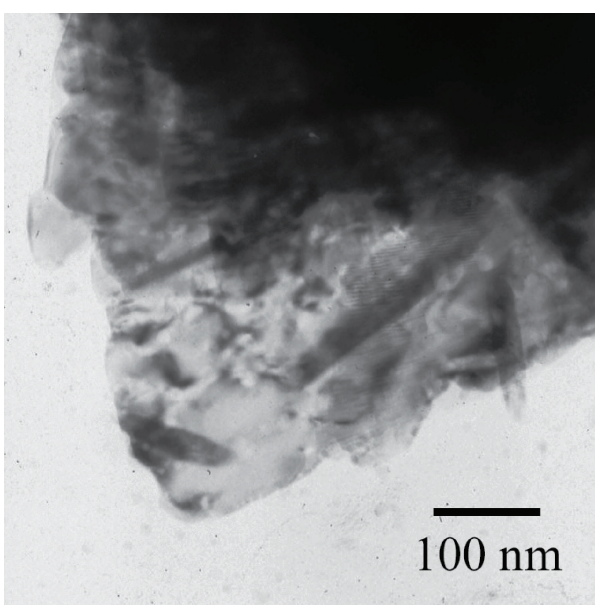

(c)

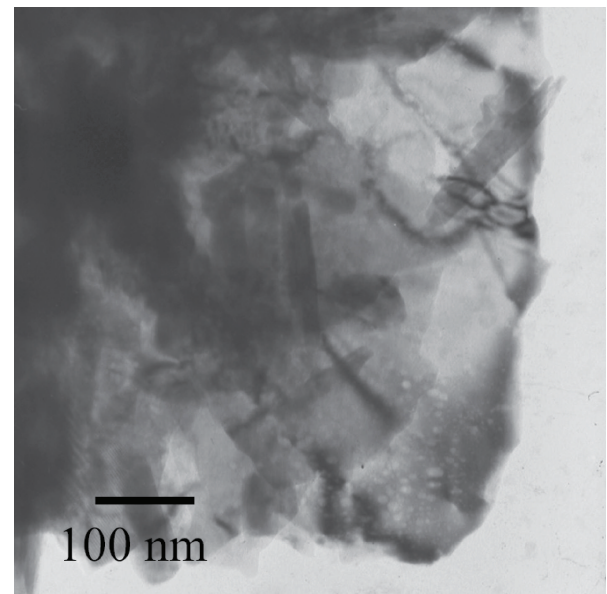

(b)

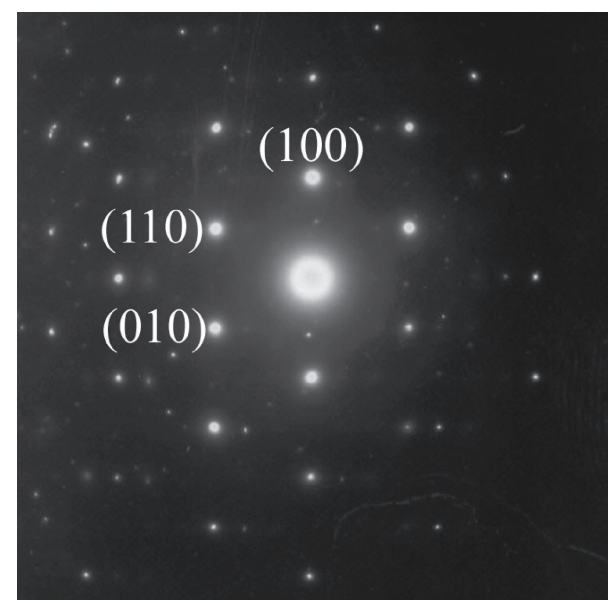

(d)

FIGURE 5: TEM images and SAED pattern of plate-like 3\% Eu-doped $\mathrm{ZnO}$ flowers.

diameters of 200-500 nm, while a very small number of $\mathrm{ZnO}$ rods having diameters more than $500 \mathrm{~nm}$ were also observed. In the flower architecture, the rods fused together at one end and pointed out at the other end. Some dispersed rods were observed in the $\mathrm{ZnO}$ products as well. Each $\mathrm{ZnO}$ rod possessed the average diameter in the range of $250 \pm 20 \mathrm{~nm}$. Moreover, the hexagonal $\mathrm{ZnO}$ nanorods are tapered at their tips and exhibit clean and smooth surface throughout their lengths. However, SEM image of 3\% Eu-doped $\mathrm{ZnO}$ presents two-dimension (2D) plate-like flower structure. It reveals that the detailed morphology of $\mathrm{ZnO}$ product is well-defined flower-like three-dimension (3D) structure with diameters in the range of $2-4 \mu \mathrm{m}$ assembled by many densely arranged nanoplates as petals. A close-up view of the nanoplates-built flower-like nanostructures reveals that they are about $70 \mathrm{~nm}$ thick, and they alternately connect with each other to form a network-like surface of the flowers.

The flower-like rod-shaped profile was further characterized by a typical TEM image. The detailed morphological characterization of the as-synthesized hexagonal pyramid tip $\mathrm{ZnO}$ nanorods assembled flowers is further analyzed by TEM (Figure 4). They show the hexagonal pyramid tip $\mathrm{ZnO}$ nanorods which were assembled in flower clusters in consistent with the FE-SEM results in terms of their morphology and dimensions. A selected area electron diffraction (SAED) pattern of single hexagonal pyramid tip $\mathrm{ZnO}$ nanorod exhibiting a spot electron diffraction pattern. It confirms that single hexagonal pyramid tip $\mathrm{ZnO}$ nanorod is a single crystalline structure. SAED pattern was indexed to hexagonal wurtzite $\mathrm{ZnO}$ structure, preferentially grown along the [001] direction of hexagonal $\mathrm{ZnO}$ phase.

The morphological structure of $3 \% \mathrm{Eu}$-doped $\mathrm{ZnO}$ sample was further examined by TEM as shown in Figure 5. The TEM images further show that 3\% Eu-doped $\mathrm{ZnO}$ sample is an irregular flower-like architecture, consistent with the SEM observation. TEM images taken from the edges of the individual structure (Figures 5(b) and 5(c)) reveal that the assynthesized sample is highly crystallized and self-assembled with nanoplates. They are very thin and transparent to the electron beam. A SAED pattern shows an array of clear and regular diffraction spots of a single nanoplate, implying that the nanoplate is single-crystalline structure in nature. Thus, 


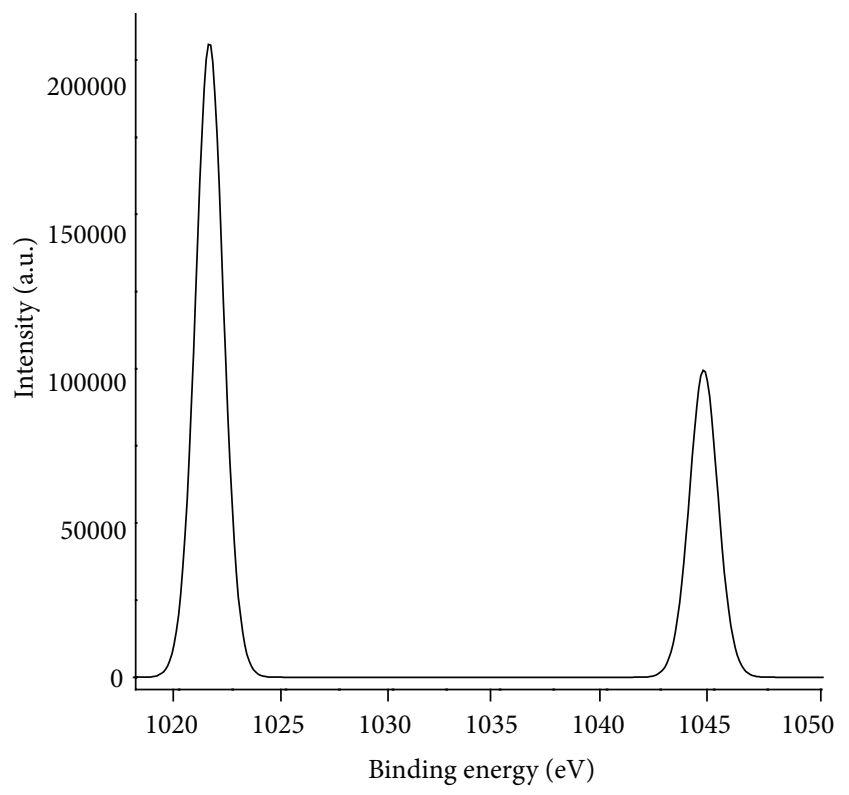

(a)

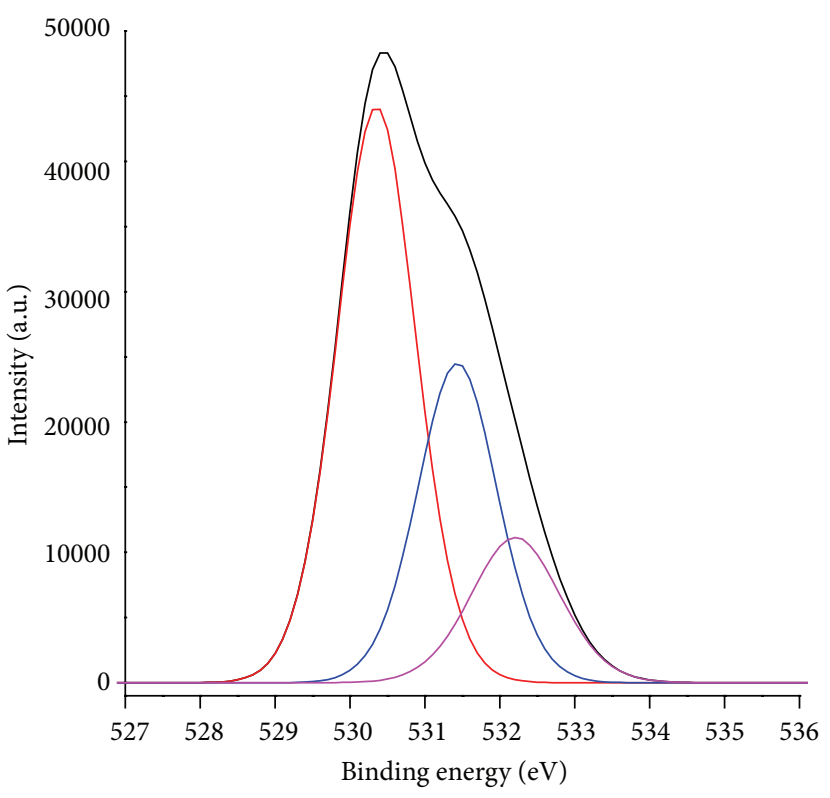

(b)

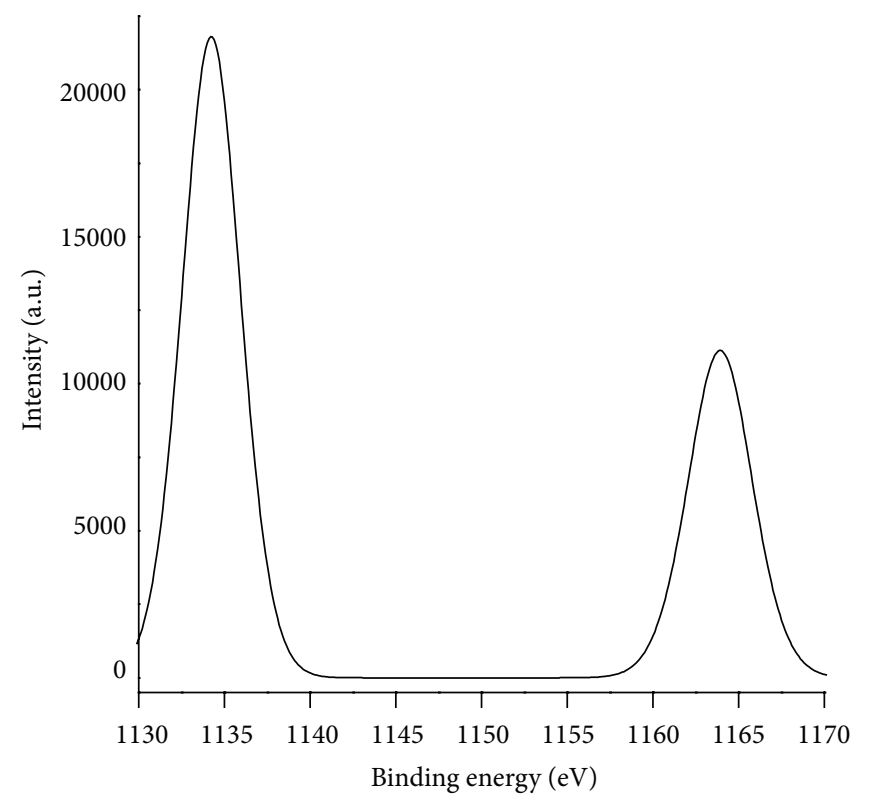

(c)

FIgURE 6: XPS spectra of (a) Zn 2p, (b) O 1s, and (c) Eu 3 d of 3\% Eu-doped ZnO.

the formation of 3\% Eu-doped $\mathrm{ZnO}$ hierarchical composites originates from the self-assembly of these single-crystalline nanoplates. The SAED was indexed to the (100), (110), and (010) planes of hexagonal $\mathrm{ZnO}$ structure which is normal to the horizontal plane of the hexagonal $\mathrm{ZnO}$ nanoplate. It is suggested that growth of the individual $\mathrm{ZnO}$ hexagonal nanoplates is along the six symmetric directions of $\pm[100]$, $\pm[110]$, and $\pm[010]$ but the typical growth along the [001] direction was suppressed [23-26], directly leading to the formation of hexagonal zinc oxide nanoplates.

XPS was used to characterize the detailed chemical composition of the 3\% Eu-doped $\mathrm{ZnO}$ as shown in Figure 6 and was calibrated using the carbon peak (C-1s) at $285.1 \mathrm{eV}$ as reference. Figure 6(a) shows the XPS spectra of the Zn$2 \mathrm{p}$ core level region. It shows doublet peaks at $1021.46 \mathrm{eV}$ and $1044.53 \mathrm{eV}$, corresponding to the $\mathrm{Zn} 2 \mathrm{p}_{3 / 2}$ and $2 \mathrm{p}_{1 / 2}$ core levels, respectively $[18,27,28]$. Energy difference of the two peaks is $23.07 \mathrm{eV}$, which agrees well with the standard value of $22.97 \mathrm{eV}$, revealing the presence of $\mathrm{Zn}^{2+}$ ions in the oxide $[18,28]$. The asymmetric feature observed in the $\mathrm{O} 1 \mathrm{~s}$ peak at $530.6 \mathrm{eV}$ is shown in Figure 6(b). It was deconvoluted by three subspectral components: stoichiometric $\mathrm{ZnO}(530.33 \mathrm{eV})$, chemisorbed oxygen on the sample $(531.42 \mathrm{eV})$, and hydroxyl species on the sample $(532.22 \mathrm{eV})[28,29]$. The Eu-3d XPS in 


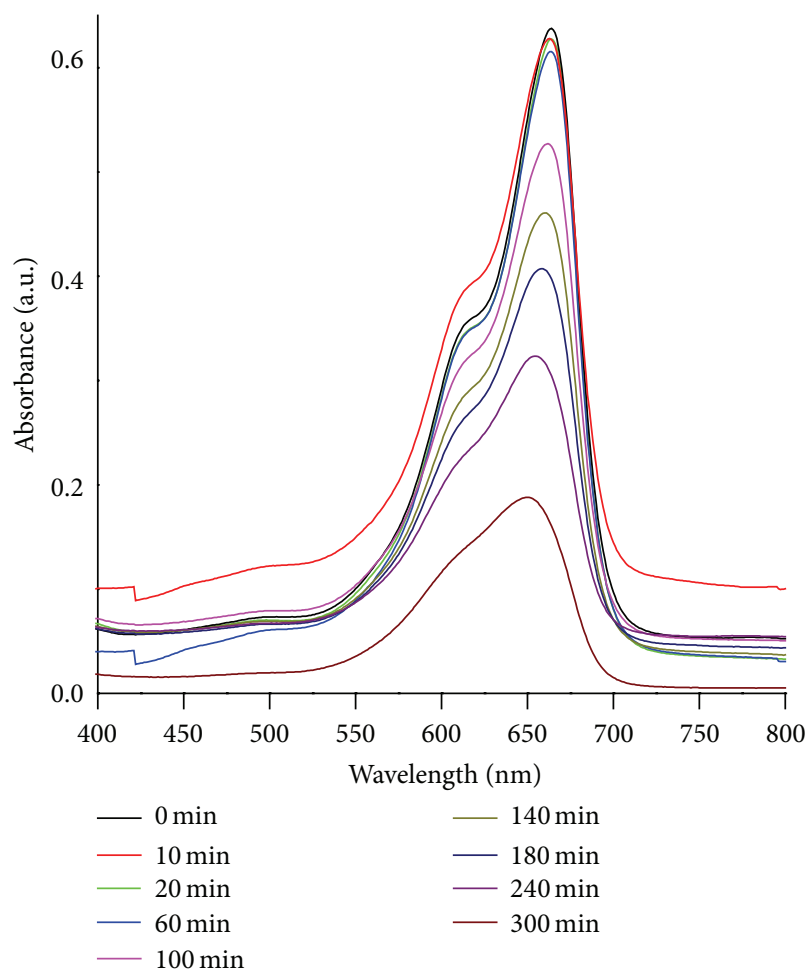

(a)

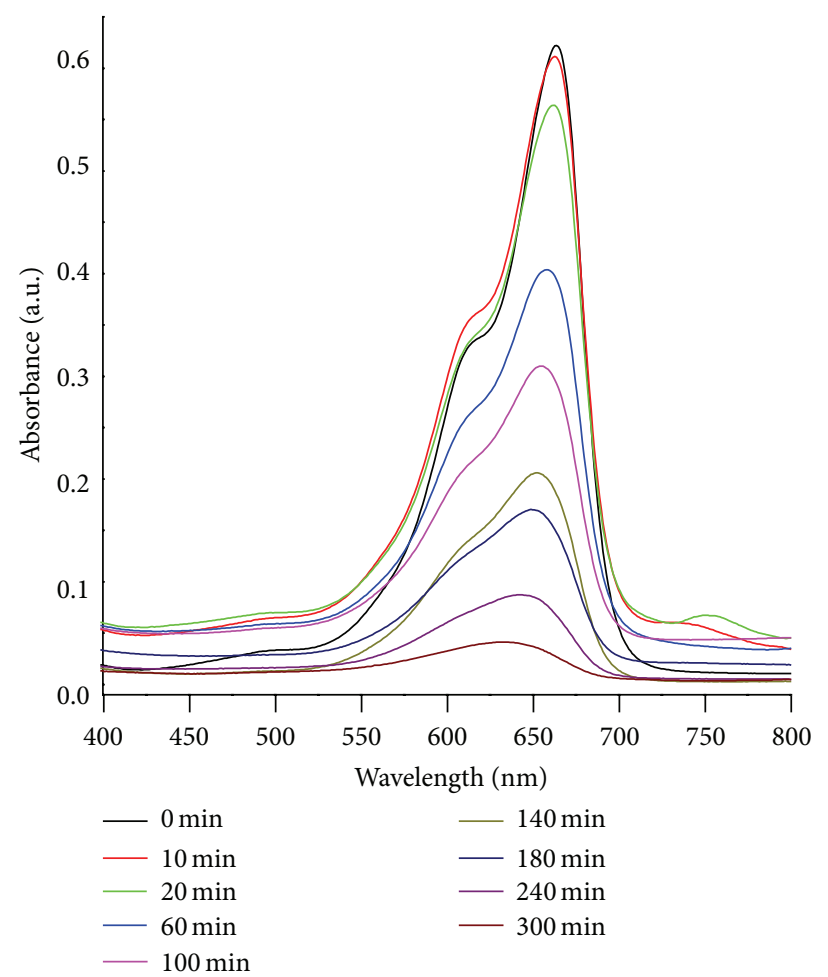

(b)

FIGURE 7: Vibration of the absorption spectra for MB solutions containing (a) undoped $\mathrm{ZnO}$ and (b) 3\% Eu-doped $\mathrm{ZnO}$ under UV light for different time intervals.

the region of the Eu-doped $\mathrm{ZnO}$ nanorod samples is shown in Figure 6(c). These two doublet binding energy regions could be assigned to the $\mathrm{Eu}^{3+} 3 \mathrm{~d}_{5 / 2}$ and $3 \mathrm{~d}_{3 / 2}$ core levels at 1134.21 and $1163.90 \mathrm{eV}[18,27,29]$. The fact that only cationic $\mathrm{Eu}^{3+}$ species were detected in the sample suggests the incorporation of $\mathrm{Eu}^{3+}$ ions into the $\mathrm{ZnO}$ matrix.

The as-synthesized $0-3 \%$ Eu-doped $\mathrm{ZnO}$ samples are used as photocatalysts to study photocatalytic activity towards the efficient degradation of methylene blue (MB) as organic dye. Figure 7 shows the UV-visible absorption spectra of degraded MB over the undoped and 3\% Eu-doped $\mathrm{ZnO}$ under UV light illumination within 0-300 min over the wavelength range of $400-800 \mathrm{~nm}$. It can be seen that the maximum absorption at $\lambda_{\text {peak }}=664 \mathrm{~nm}$ of $\mathrm{MB}$ dye is continuously decreased with the increase of exposure time from 0 to $300 \mathrm{~min}$. The decrease in the relative intensities of absorption of 3\% Eu-doped $\mathrm{ZnO}$ is faster than that of pure $\mathrm{ZnO}$ which indicates that the Eu doping improves the effective performance degradation of dye under UV light illumination.

Figure 8(a) shows the photocatalytic activity of the undoped and Eu-doped $\mathrm{ZnO}$ samples. The blank experiment in the absence of photocatalyst demonstrated that $\mathrm{MB}$ was not photodegraded by the UV light. During photocatalysis, all the photocatalysts exhibited the photocatalytic activity in $\mathrm{MB}$ photodegradation under UV light irradiation, confirming that photocatalyst plays a role in the degradation of $\mathrm{MB}$ under $\mathrm{UV}$ light. $\mathrm{ZnO}$ is an effective photocatalyst in photodegradation of $\mathrm{MB}$ solution of $75.00 \%$, lower in the photodegradation of the $\mathrm{MB}$ solution than Eu-doped $\mathrm{ZnO}$. The 3\% Eu-doped $\mathrm{ZnO}$ has the highest photocatalytic activity. The MB degradation efficiency of $3 \%$ Eu-doped $\mathrm{ZnO}$ reaches the $90.51 \%$, which is 1.20 and 1.10 times higher than those of the pure $\mathrm{ZnO}$ and $1 \%$ Eu-doped $\mathrm{ZnO}$, respectively.

Photocatalytic activity for degradation of $\mathrm{MB}$ obeys the pseudo-first-order reaction kinetics $[1,2,10]$ with $k$ as the rate constant and $t$ as the $\mathrm{UV}$ irradiation time given by

$$
C_{t}=C_{0} e^{-k t} \text {. }
$$

Figure $8(\mathrm{~b})$ shows the plots of $\ln \left(C_{0} / C_{t}\right)$ versus the irradiation time for the photodegradation of $\mathrm{MB}$. In this research, the photodegradation followed very well with the pseudofirst-order kinetics with $R^{2}=0.9556,0.9779$, and 0.9959 for 0 , 1, and 3\% Eu-doped $\mathrm{ZnO}$, respectively. The rate constants for degradation of $\mathrm{MB}$ on 0,1 , and $3 \%$ Eu-doped $\mathrm{ZnO}$ are $3.43 \times$ $10^{-3}, 4.53 \times 10^{-3}$, and $7.73 \times 10^{-3} \mathrm{~min}^{-1}$, respectively. The rate constants for degradation of $\mathrm{MB}$ by $3 \%$ Eu-doped $\mathrm{ZnO}$ increase the reaction rate by about 2.25 times compared to pure $\mathrm{ZnO}$. In general, performance activity of photocatalysts was determined by the delay of photogenerated electron-hole recombination rate. Therefore, enhancing the photocatalytic activity by doping $\mathrm{ZnO}$ nanostructure with a proper mole fraction of $\mathrm{Eu}^{+3}$ ions is attributed to increase in the electronhole life time. 


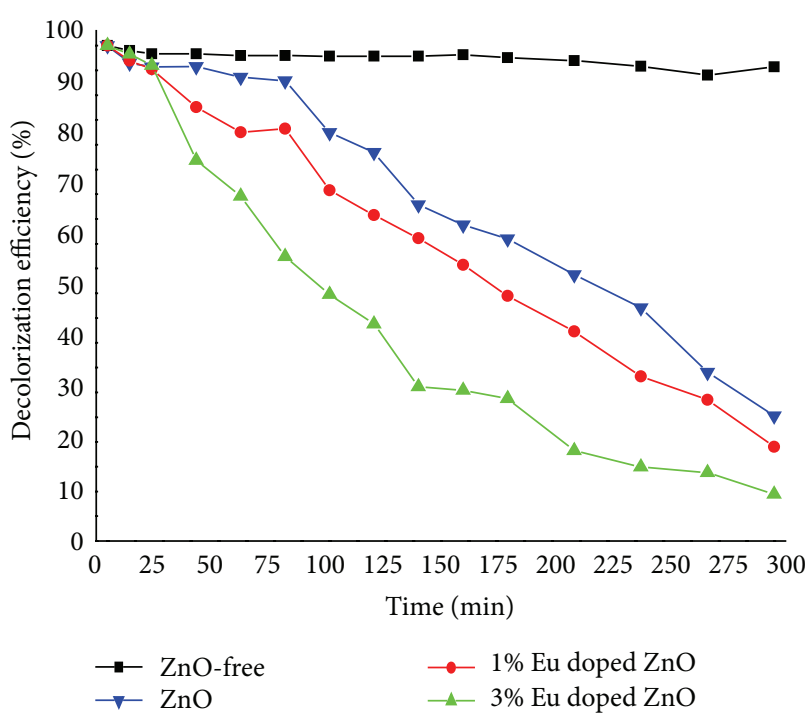

(a)

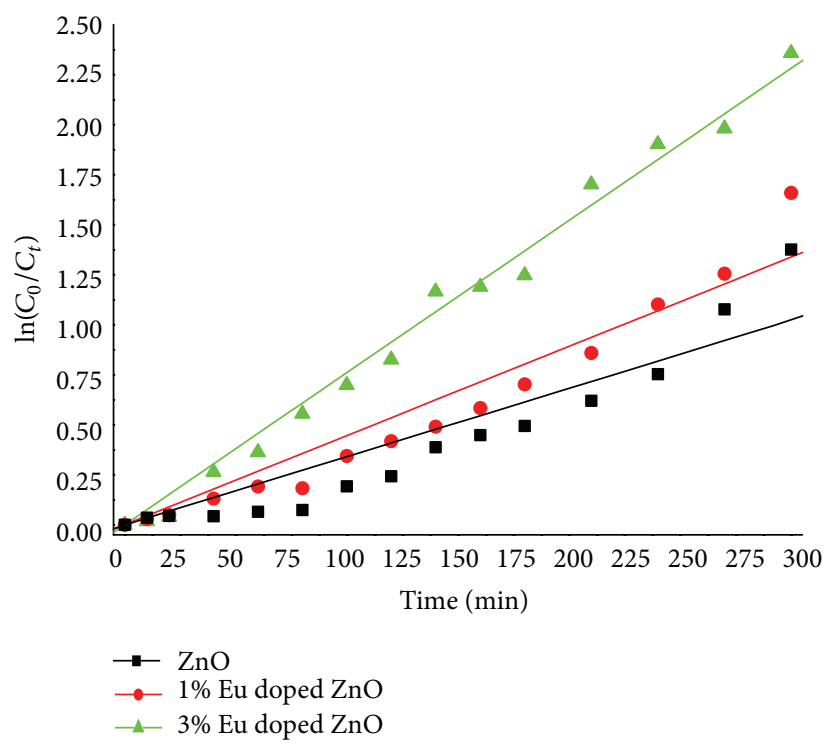

(b)

FIGURE 8: (a) Photodegradation efficiency and (b) reaction kinetics of the MB aqueous solutions of different percentages of Eu-doped ZnO under UV light within $300 \mathrm{~min}$.

\section{Conclusions}

Single crystalline $\mathrm{ZnO}$ and Eu-doped $\mathrm{ZnO}$ have been successfully synthesized by a sonochemical process. The characterization results show that the as-synthesized $\mathrm{ZnO}$ and Eudoped $\mathrm{ZnO}$ photocatalysts belong to the hexagonal wurtzite structure. The photocatalytic activities of the as-synthesized $\mathrm{ZnO}$ and Eu-doped $\mathrm{ZnO}$ photocatalysts have been evaluated by the degradation of $\mathrm{MB}$ in aqueous solutions under $\mathrm{UV}$ light. The $\mathrm{MB}$ decolorization efficiency of 3\% Eu-doped $\mathrm{ZnO}$ is achieved at $90.51 \%$ within $300 \mathrm{~min}$, higher than that of pure $\mathrm{ZnO}$.

\section{Conflict of Interests}

The authors declare that there is no conflict of interests regarding the publication of this paper.

\section{Acknowledgment}

The authors are extremely grateful to the Prince of Songkla University, Thailand, under Contact no. SCI560495S.

\section{References}

[1] Y. Tian, L. Zhang, and J. Zhang, "A superior visible light-driven photocatalyst: europium-doped bismuth tungstate hierarchical microspheres," Journal of Alloys and Compounds, vol. 537, pp. 24-28, 2012.

[2] J. Xu, Y. Ao, D. Fu, and C. Yuan, "A simple route for the preparation of $\mathrm{Eu}, \mathrm{N}$-codoped $\mathrm{TiO} 2$ nanoparticles with enhanced visible light-induced photocatalytic activity," Journal of Colloid and Interface Science, vol. 328, no. 2, pp. 447-451, 2008.
[3] J.-H. Sun, S.-Y. Dong, Y.-K. Wang, and S.-P. Sun, "Preparation and photocatalytic property of a novel dumbbell-shaped $\mathrm{ZnO}$ microcrystal photocatalyst," Journal of Hazardous Materials, vol. 172, no. 2-3, pp. 1520-1526, 2009.

[4] M. Faisal, S. B. Khan, M. M. Rahman, A. Jamal, and M. M. Abdullah, "Fabrication of $\mathrm{ZnO}$ nanoparticles based sensitive methanol sensor and efficient photocatalyst," Applied Surface Science, vol. 258, pp. 7515-7522, 2012.

[5] S. B. Khan, M. Faisal, M. M. Rahman, and A. Jamal, "Lowtemperature growth of $\mathrm{ZnO}$ nanoparticles: photocatalyst and acetone sensor," Talanta, vol. 85, no. 2, pp. 943-949, 2011.

[6] M. Khatamian, A. A. Khandar, B. Divband, M. Haghighi, and S. Ebrahimiasl, "Heterogeneous photocatalytic degradation of 4nitrophenol in aqueous suspension by $\mathrm{Ln}\left(\mathrm{La}^{3+}, \mathrm{Nd}^{3+}\right.$ or $\left.\mathrm{Sm}^{3+}\right)$ doped ZnO nanoparticles," Journal of Molecular Catalysis A, vol. 365, pp. 120-127, 2012.

[7] J. Li, G. Lu, Y. Wang, Y. Guo, and Y. Guo, "A high activity photocatalyst of hierarchical 3D flowerlike $\mathrm{ZnO}$ microspheres: synthesis, characterization and catalytic activity," Journal of Colloid and Interface Science, vol. 377, pp. 191-196, 2012.

[8] J. C. Sin, S. M. Lam, K. T. Lee, and A. R. Mohamed, "Photocatalytic performance of novel samarium-doped spherical-like $\mathrm{ZnO}$ hierarchical nanostructures under visible light irradiation for 2, 4-dichlorophenol degradation," Journal of Colloid and Interface Science, vol. 401, pp. 40-49, 2013.

[9] Y. Liu, H. Lv, S. Li, X. Xing, and G. Xi, "Preparation and photocatalytic property of hexagonal cylinder-like bipods $\mathrm{ZnO}$ microcrystal photocatalyst," Dyes and Pigments, vol. 95, Article ID 443e449, 2012.

[10] Q. I. Rahman, M. Ahmad, S. K. Misra, and M. B. Lohani, "Hexagonal $\mathrm{ZnO}$ nanorods assembled flowers for photocatalytic dye degradation: growth, structural and optical properties," Superlattices and Microstructures, vol. 64, pp. 495-506, 2013.

[11] F. Xu, J. Chen, L. Guo, S. Lei, and Y. Ni, "In situ electrochemically etching-derived $\mathrm{ZnO}$ nanotube arrays for highly efficient and 
facilely recyclable photocatalyst," Applied Surface Science, vol. 258, pp. 8160-8165, 2012.

[12] C. C. Lin and L. J. Hsu, "Removal of polyvinyl alcohol from aqueous solutions using $\mathrm{P}-25 \mathrm{TiO}_{2}$ and $\mathrm{ZnO}$ photocataysts: a comparative study," Powder Technology, vol. 246, pp. 351-355, 2013.

[13] O. Yayapao, S. Thongtem, A. Phuruangrat, and T. Thongtem, "Sonochemical synthesis, photocatalysis and photonic properties of 3\% Ce-doped $\mathrm{ZnO}$ nanoneedles," Ceramics International, vol. 39, pp. S563-S568, 2013.

[14] O. Yayapao, T. Thongtem, A. Phuruangrat, and S. Thongtem, "Ultrasonic-assisted synthesis of Nd-doped $\mathrm{ZnO}$ for photocatalysis," Materials Letters, vol. 90, pp. 83-86, 2013.

[15] O. Yayapao, T. Thongtem, A. Phuruangrat, and S. Thongtem, "Sonochemical synthesis of Dy-doped $\mathrm{ZnO}$ nanostructures and their photocatalytic properties," Journal of Alloys and Compounds, vol. 576, pp. 72-79, 2013.

[16] S. Yao, C. Sui, and Z. Shi, "Preparation and characterization of visible-light-driven europium doped mesoporous titania photocatalyst," Journal of Rare Earths, vol. 29, no. 10, pp. 929933, 2011.

[17] Powder Diffract, "File, JCPDS Internat," Centre Diffract, Data, PA, 19073-3273, USA, 2001.

[18] J. Yang, X. Li, J. Lang et al., "Synthesis and optical properties of Eu-doped $\mathrm{ZnO}$ nanosheets by hydrothermal method," Materials Science in Semiconductor Processing, vol. 14, no. 3-4, pp. 247252, 2011.

[19] M. Wang, C. Huang, Z. Huang et al., "Synthesis and photoluminescence of Eu-doped $\mathrm{ZnO}$ microrods prepared by hydrothermal method," Optical Materials, vol. 31, no. 10, pp. 1502-1505, 2009.

[20] S. Husain, L. A. Alkhtaby, E. Giorgetti, A. Zoppi, and M. M. Miranda, "Effect of Mn doping on structural and optical properties of sol gel derived $\mathrm{ZnO}$ nanoparticles," Journal of Luminescence, vol. 145, pp. 132-137, 2014.

[21] P. S. Kumar, P. Paik, A. D. Raj et al., "Biodegradability study and $\mathrm{pH}$ influence on growth and orientation of $\mathrm{ZnO}$ nanorods via aqueous solution process," Applied Surface Science, vol. 258, pp. 6765-6771, 2012.

[22] N. K. Hassan and M. R. Hashim, "Flake-like ZnO nanostructures density for improved absorption using electrochemical deposition in UV detection," Journal of Alloys and Compounds, vol. 577, pp. 491-497, 2013.

[23] D. Chu, Y. Zeng, and D. Jiang, "Controlled growth and properties of $\mathrm{Pb}^{2+}$ doped $\mathrm{ZnO}$ nanodisks," Materials Research Bulletin, vol. 42, no. 5, pp. 814-819, 2007.

[24] C. X. Xu, G. P. Zhu, J. Kasim et al., "Spatial distribution of defect in ZnO nanodisks," Current Applied Physics, vol. 9, no. 3, pp. 573-576, 2009.

[25] M. Wang, S. H. Hahn, J. S. Kim, J. S. Chung, E. J. Kim, and K.-K. Koo, "Solvent-controlled crystallization of zinc oxide nano(micro)disks," Journal of Crystal Growth, vol. 310, no. 6, pp. 1213-1219, 2008.

[26] C. X. Xu, X. W. Sun, Z. L. Dong, and M. B. Yu, "Zinc oxide nanodlsk," Applied Physics Letters, vol. 85, no. 17, pp. 3878-3880, 2004.

[27] P. Mohanty, B. Kim, and J. Park, "Synthesis of single crystalline europium-doped $\mathrm{ZnO}$ nanowires," Materials Science and Engineering B: Solid-State Materials for Advanced Technology, vol. 138, no. 3, pp. 224-227, 2007.
[28] D. D. Wang, G. Z. Xing, J. H. Yang et al., "Dependence of energy transfer and photoluminescence on tailored defects in Eudoped $\mathrm{ZnO}$ nanosheets-based microflowers," Journal of Alloys and Compounds, vol. 504, no. 1, pp. 22-26, 2010.

[29] J. Sin, S. Lam, I. Satoshi, K. Lee, and A. R. Mohamed, "Sunlight photocatalytic activity enhancement and mechanism ofnovel europium-doped $\mathrm{ZnO}$ hierarchical micro/nanospheres fordegradation of phenol," Applied Catalysis B, vol. 148-149, pp. 258-268, 2014. 

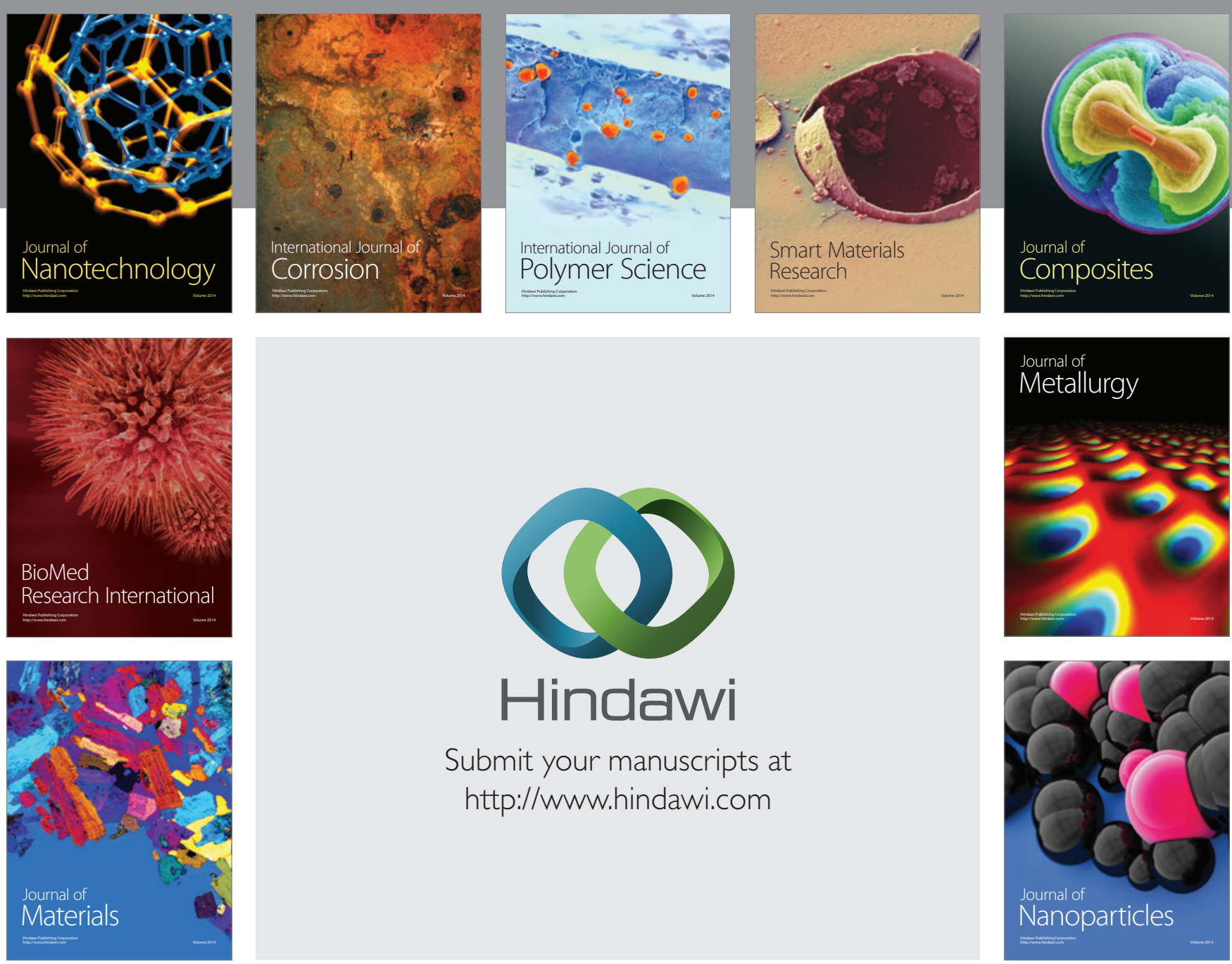

Submit your manuscripts at http://www.hindawi.com
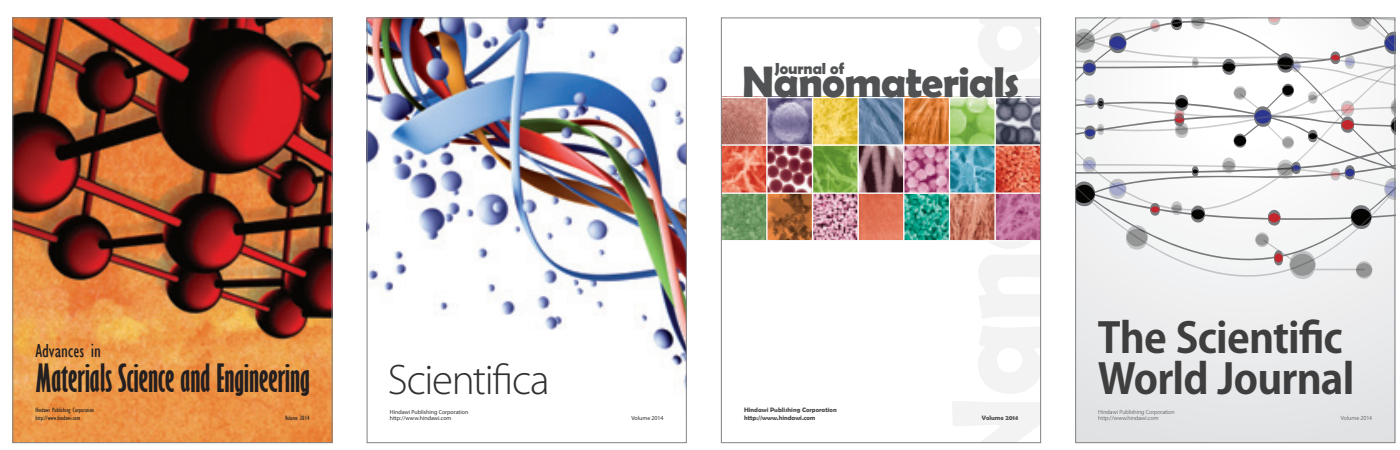

\section{The Scientific World Journal}
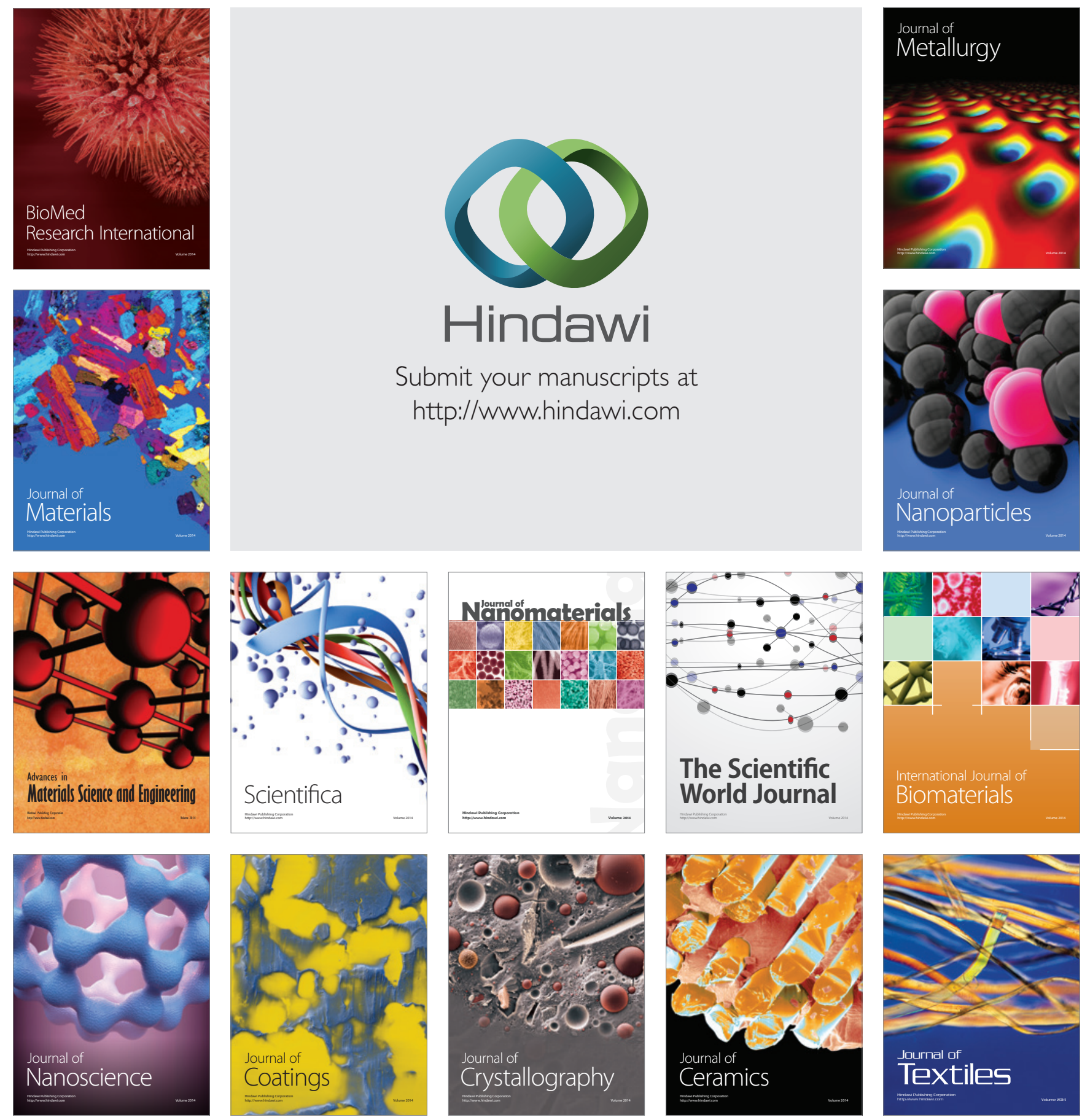